\title{
Pelatihan Desain Grafis Menggunakan Perangkat Adobe Photoshop Untuk Manipulasi Foto Bagi Tim Teknologi Informasi YPU
}

\author{
Mira Ziveria' ${ }^{1)}$, Ridha Sefina Samosir ${ }^{2}$, Muhammad Rusli ${ }^{3)}$ \\ Sistem Informasi, Institut Teknologi dan Bisnis Kalbis \\ Jalan Pulomas Selatan Kav 22 Jakarta Timur 13210 \\ ${ }^{1)}$ Email: ridha.samosir@kalbis.ac.id \\ ${ }^{2) E m a i l: m i r a . z i v e r i a @ k a l b i s . a c . i d}$ \\ ${ }^{3)}$ Email: Muhammad.rusli@kalbis.ac.id
}

\begin{abstract}
Yayasan Prima Unggul (YPU) is an entrepreneurial-based school that wants to realize the dream of giving birth to 10000 new emterpreneur from orphanages and underprivileged families. The problem faced is the lack of professional staff in the field of entrepreneurship development and assistance. This activity aims to conduct training on graphic design using Adobe Photoshop to manipulate photos for the Prima Unggul Foundation information technology team on March 13, 2014 at the Kalbis Institute computer laboratory on Jalan Pulomas Selatan Kav.22. Pulomas, East Jakarta. The training was given by the Kalbis Institute Information Systems Study Program lecturer.
\end{abstract}

Keywords: adobe photoshop, graphic design, information technology, training

\begin{abstract}
Abstrak: Yayasan Prima Unggul (YPU) merupakan sekolah berbasis kewirausahaan yang ingin mewujudkan impian untuk melahirkan 10000 emterpreneur baru dari panti asuhan dan keluarga kurang mampu. Permasalahan yang dihadapi adalah kurangnya tenaga profesional untuk bidang pengembangan dan pendampingan kewirausahaan. Kegiatan ini bertujuan untukmengadakan pelatihan tentang desain grafis menggunakan perangkat Adobe Photoshop untuk melakukan manipulasi foto bagi tim teknologi informasi Yayasan Prima Unggul tanggal 13 Maret 2014 di laboratorium komputer Kalbis Institute Jalan Pulomas Selatan Kav.22. Pulomas, Jakarta Timur. Pelatihan diberikan oleh dosen Program Studi Sistem Informasi Kalbis Institute.
\end{abstract}

Kata kunci: Adobe Photoshop, desain grafis, pelatihan, teknologi informasi

\section{PENDAHULUAN}

Yayasan Prima Unggul (YPU) merupakan sebuah sekolah berbasis kewirausahaan yang secara konsisten menerapkan kurikulum holistik dengan menyajikan secara proporsional: perubahan mindset, pembentukan karakter, bidang akademik dan praktik ketrampilan serta pengembangan bakat dan talenta.

Yayasan Prima Unggul ingin mewujudkan impiannya yakni "Melahirkan 10000 entrepreneur baru dari panti asuhan dan keluarga kurang mampu" dengan cara menjadikan mereka mandiri dan berdampak positif bagi orang lain, yaitu membantu para siswa menjadi pencipta lapangan kerja bagi dirinya sendiri dan orang lain serta berdampak bagi sesama. Target yang ingin dicapai adalah masa pendidikan 3 tahun menghasilkan output berupa SDM mandiri dan berdampak. Para alumni melanjutkan unit kewirausahaan dan YPU bersinergi dengan berbagai perguruan tinggi untuk mendapatkan beasiswa prestasi. Setelah lulus kuliah, para alumni kembali ke daerah asal untuk membangun dan mengembangkan potensi daerah dalam kerja sama dengan wadah alumni YPU.

YPU telah memiliki beberapa unit usaha, yaitu: Training Center, Rumah Makan, Travel, Dawet Ireng, Cucian Motor, dan sedang merencanakan pengembangan unit usaha baru yaitu Tanaman dan pupuk Organik serta bakery. Untuk bisa mewujudkan mimpi dan target YPU memiliki tantangan yaitu motivasi dan karakter kurang optimal, konsep-konsep akademik masih terbatas dan praktek kewirausahaan masih menggunakan cara konvensional.

Beberapa hambatan bagi YPU diantaranya fasilitas pendukung terbatas, seperti ruangan-ruangan, sarana IT dan sarana pelatihan. Hambatan lainnya 
adalah kurangnya tenaga professional untuk bidang pengembangan dan pendampingan kewirausahaan. Kebutuhan riil YPU adalah perlu adanya kemitraan dalam sarana IT dan laboratorium pengembangan diri. Selain itu perlu adanya guru atau dosen pengajar atau tutor.

Sehubungan dengan hal tersebut di atas dan dalam rangka mewujudkan salah satu Tri Dharma Perguruan Tinggi yaitu pengabdian kepada masyarakat, program studi Sistem Informasi akan mengusulkan program pelatihan desain grafis menggunakan perangkat Adobe Photoshop untuk melakukan manipulasi foto bagi tim teknologi informasi Yayasan Prima Unggul tanggal 13 Maret 2014 jam 08.00 - 17.00 WIB di laboratorium komputer kampus Kalbis Institute Jalan Pulomas Selatan Kav.22. Pulomas, Jakarta Timur.

Yayasan Prima Unggul didirikan oleh Bpk. Martinus Mesarudi Gea bersama beberapa pemerhati sosial lintas agama, suku dan ras. Berdirinya yayasan/sekolah ini tidak terlepas dari keprihatinan Pak Martin atas realitas pendidikan Indonesia umumnya dan di panti-panti asuhan khususnya. Keprihatinan itu berawal dari sebuah pengalaman yang menyentak batinnya. Dalam kunjungannya selaku Koordinator FKPA Pusat ke sebuah panti jompo, Pak Martin dikejutkan oleh pernyataan salah seorang penghuninya: "Nak Martin, Nenek dulu waktu kecil tinggal di panti, anak nenek juga pernah tinggal di panti, dan saat ini cucu nenek pun tinggal di panti." Sejak saat itu, Pak Martin terus menganalisa fenomena penghuni panti yang secara turun-temurun tinggal di panti asuhan.

Analisa dan refleksi yang terus-menerus itu kemudian mengerucut pada kesadaran tentang penyebab fenomena ini, yaitu adanya pandangan tentang panti asuhan sebagai tempat tinggal anakanak kurang beruntung, orang yang tidak berdaya dan patut dikasihani. Pandangan seperti ini membuat para pengurus panti berjuang keras untuk menyediakan berbagai kebutuhan dan fasilitas. Gambaran demikian juga membangkitkan rasa iba dan kasihan para donatur sehingga mereka terdorong untuk memberikan berbagai kebutuhan untuk mendukung para pengurus panti. Paradigma yang salah tentang anak panti mengakibatkan anak panti pun memandang diri mereka sendiri sebagai obyek belas kasihan yang tidak berdaya dan hanya bergantung pada pengurus dan donatur. Amatlah wajar kalau akhirnya anak panti menerima kenyataan bahwa mereka adalah generasi miskin yang tidak mampu menghidupi diri dan keluarga sendiri kelak, sehingga panti asuhan selalu menjadi sinterklas yang juga akan menerima dan menampung anak-anak mereka. Dengan ini, tanpa disadari sebuah lingkaran kemiskinan telah dilestarikan oleh stakeholder panti asuhan.

Kesadaran ini kemudian menjadi dorongan kuat dalam diri Pak Martin untuk melakukan sesuatu demi menjawab keprihatinannya. Beliau membangun impian tentang pendidikan dan pendampingan yang menjadikan anak-anak panti sebagai pribadipribadi manusia yang mandiri. Impian itu kemudian diwujudkan dalam tindakan nyata. Setelah berdialog dan membangun kerja sama dengan beberapa pemerhati sosial, pada tanggal 11 Februari 2011, Pak Martin mendirikan Yayasan Prima Unggul. Di dalam dan melalui Yayasan Prima Unggul, keprihatinan/ kegelisahan terhadap lingkaran kemiskinan anak panti diubah menjadi impian yakni "Melahirkan 10000 entrepreneur baru dari panti asuhan dan keluarga kurang mampu" dengan cara menjadikan mereka mandiri dan berdampak positif bagi orang lain. Yayasan Prima Unggul hadir sebagai sebuah sekolah berbasis kewirausahaan yang secara konsisten menerapkan kurikulum holistik dengan menyajikan secara proporsional: perubahan mindset, pembentukan karakter, bidang akademik dan praktik ketrampilan serta pengembangan bakat dan talenta.

Hingga saat ini, Yayasan Prima Unggul sudah berjalan dengan baik selama hampir tiga tahun. Dari waktu ke waktu, YPU terus membangaun kemitraan dengan berbagai pihak, seperti donatur, perusahaan dan lembaga pendidikan tinggi. Beberapa unit usaha dibuka dan dikembangkan sebagai sarana praktik kerja nyata bagi siswa dan siswinya. Menjelang ulang tahunnya yang ketiga ini, YPU telah memiliki beberapa unit usaha, yaitu: Training Center, Rumah Makan, Travel, Dawet Ireng, Cucian Motor, dan sedang merencanakan pengembangan unit usaha baru yaitu Tanaman dan pupuk Organik serta bakery. Tentu saja perjalanan YPU tidak tanpa Tantangan dan rintangan. Tantangan paling riil yang dihadapi ialah bahwa status dan legalitas sekolah ini tidak dapat disamakan dengan sekolah formal karena implementasi kurikulum yang tidak mengikuti standarisasi pemerintah. Status ini pun menjadikan Sekolah Prima Unggul kurang populer di mata masyarakat yang "ijazah-minded" Selain itu, gerakan perubahan memperkaya anak panti melalui beragam pemberdayaan mendapat kritikan dari para praktisi sosial tradisional yang menyebutnya sebagai upaya eksploitasi anak. Akan tetapi tantangan dan rintangan yang ada toh tidak mematahkan semangat, melainkan justru menjadi lecutan bagi YPU untuk semakin maju dan berkembang terus-menerus. Apalagi 
segala tantangan itu selalu diikuti oleh penerimaan, penghargaan dan pengakuan dari banyak pihak, yaitu bahwa YPU bukan hanya sekedar unik dan berbeda, tetapi lebih dari itu dapat menjadi pelita yang tidak berhenti bernyala di tengah suramnya realitas pendidikan di Indonesia. Selamat Ulang Tahun YPU

Yayasan Prima Unggul menerapkan kurikulum berbasis entrepreneurship yang khas dengan perhatian kepada lima aspek pendidikan, yaitu perubahan mindset, pembentukan karakter, pendidikan akademis, practical skills, dan pengembangan minat dan bakat dalam bidang seni. Secara sederhana, aspek-aspek pendidikan itu dapat dilihat pada model pendidikan YPU pada Gambar 1.

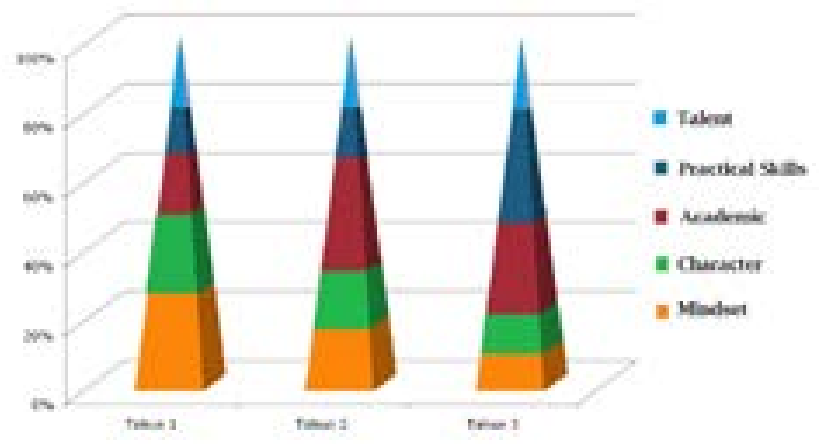

Gambar 1 Aspek pendidikan YPU

Hal pertama yang ditanamkan dalam diri anak-anak panti dan keluarga kurang mampu ialah kesadaran bahwa realitas kemiskinan yang mereka alami saat ini bukanlah takdir, melainkan kenyataan yang timbul karena dari sistem yang dikembangkan dalam kehidupan masyarakat dewasa ini cenderung menghambat dan mengkerdilkan "kekayaan" pribadi manusia. Setiap orang memiliki potensi yang dianugerahkan Tuhan, akan tetapi potensi tersebut sering tidak dapat ditumbuhkembangkan dengan baik dan benar. YPU hadir untuk mengubah pola pikir (mindset) dan menumbuhkembangkan potensi diri sesuai dengan passion setiap siswa.

YPU meyakini bahwa dari kedalaman hati yang tulus dan rendah hati, setiap potensi dapat bertumbuh dengan maksimal. Beragam nilai yang mendukung pembentukan kepribadian yang utuh digali terus menerus sehingga setiap siswa menjadi dapat menjadi pribadi berkarakter kuat. Inilah esensi pembentukan kepribadian setiap individu.

Kepemilikan ilmu pengetahuan merupakan kebutuhan dasar setiap individu. Pengembangan ilmu pengetahuan melalui proses belajar dengan beragam sumber diyakini sebagai sumber inspirasi dan ide kreatif-inovatif dalam menemukan solusi setiap persoalan kehidupan. YPU menginspirasi setiap siswa untuk menyadari bahwa kekayaan ilmu tidak hanya diukur dengan nilai (angka), melainkan melalui aplikasinya dalam menjawabi persoalan dalam kehidupan mereka.

Konsep yang bagus tetapi tidak terimplementasi dalam tindakan nyata hanya akan menjadi utopia yang tidak menjawab kebutuhan manusia. Karena itu di YPU implementasi setiap teori dan konsep yang dipelajari harus diwujudkan di lapangan dan menyapa setiap kebutuhan riil setiap individu. Unit usaha Rumah Makan, Bakery, Budidaya Lele, Pertanian Organik, Penjualan CD lagu rohani karya siswa YPU dan YKK, Jasa Cucian Motor, Jasa Travel dan Trainning Center Kewirausahaan merupakan praktik ketrampilan yang menjadikan setiap siswa sebagai subyek penentu perubahan hidupnya sendiri.

Bakat dan talenta yang dimiliki oleh setiap anak, secara khusus dalam bidang seni ditumbuhkembangkan bersama dalam komunitas dan ditujukan untuk membawa kebahagiaan bagi banyak orang. Permintaan untuk memeriahkan Ekaristi di gereja-gereja, pelayanan paduan suara untuk pemberkatan pernikahan, rekaman lagu-lagu rohani, drama musikal, hingga pentas seni dalam event internasional APEC 2013 di Bali merupakan pencapaian prestasi sekaligus pengakuan terhadap talenta dan karya seni siswa YPU.

YPU berdiri tanggal 11 Februari 2011, didirikan oleh Martinus Mesarudi Gea, Prijono Nugroho, Edwin Kow. Motto YPU adalah Pendidikan Berbasis Kewirausahaan Menuju Kemerdekaan Sejati, Visi Mewujudkan $\mathbf{1 0 0 0 0}$ entrepreneur baru lahir dari panti asuhan dan keluarga kurang mampu. Misi Membantu para siswa menjadi pencipta lapangan kerja bagi dirinya sendiri dan orang lain serta berdampak bagi sesama. Nilai SERVER (Social, Emphatic, Responsible, Visionary, Entrepreneurial, Religious). Goal Selama 3 tahun dilatih menjadi SDM mandiri dan berdampak, setelah lulus para alumni melanjutkan unit kewirausahaan dan YPU bersinergi dengan berbagai perguruan tinggi untuk mendapatkan beasiswa prestasi dan setelah lulus kuliah kembali ke daerah asal untuk membangun dan mengembangkan potensi daerah dalam kerja sama dengan wadah alumni YPU. Pembina oleh Prijono Nugroho, Pengawas Edwin Kow, Ketua Martinus Mesarudi Gea, Manajemen Pembinaan Kesiswaan Sr. M. Paul Siseng, OSU, Bidang Keuangan dan Unit Bisnis Serli Rany Liando, Bidang Pengembangan Kurikulum Rm. Lukas Bernardus Ebu Dhae, Pr, Bidang Pengembangan Kreasi Siswa Donny Satryo Wibowo, Jumlah Tenaga Pengajar 13 guru tetap dan 6 guru tamu/pelatih bisnis, Jumlah Siswa 40 orang. 
Unit usaha yang telah dikembangkan oleh YPU dapat dilihat pada Gambar 2, Gambar 3, Gambar 4, Gambar 5, Gambar 6.

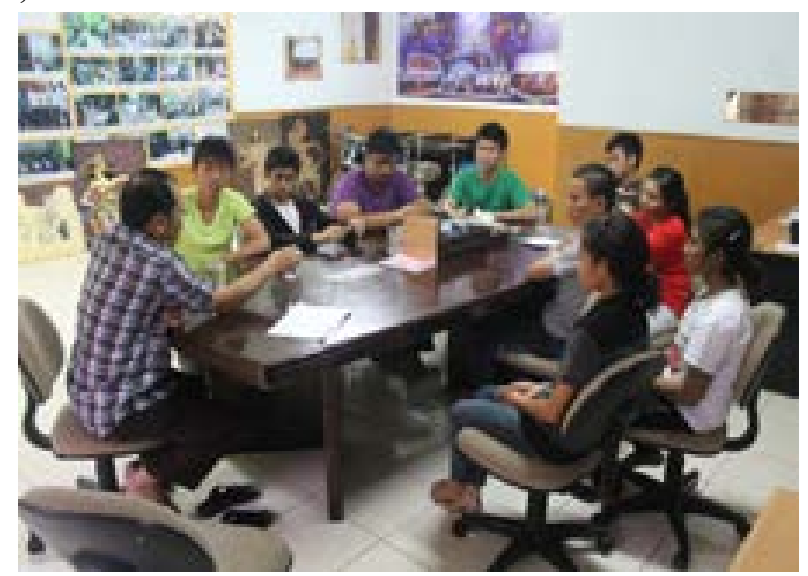

Gambar 2. Pelatihan kewirausahaan

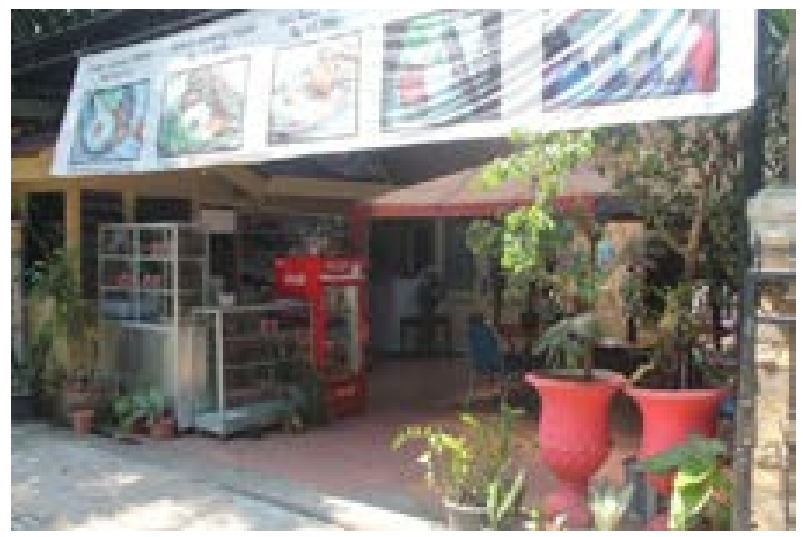

Gambar 3. Rumah makan

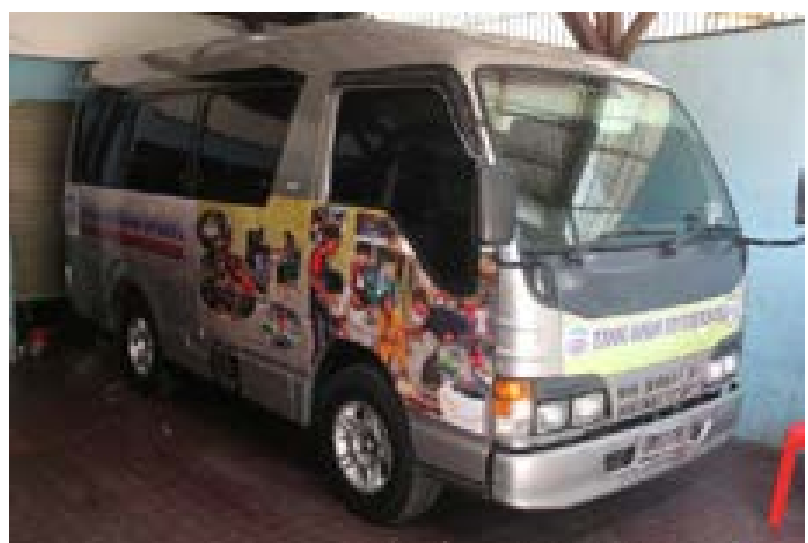

Gambar 4. Travel

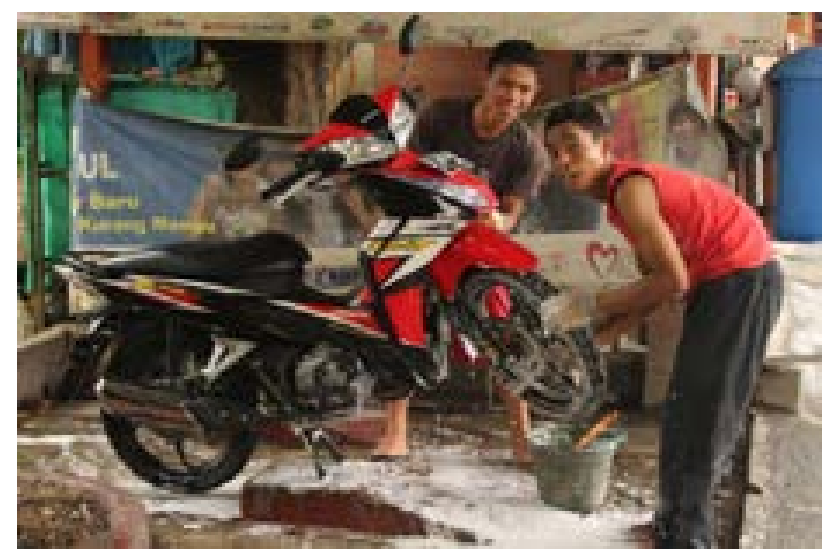

Gambar 5. Cucian motor

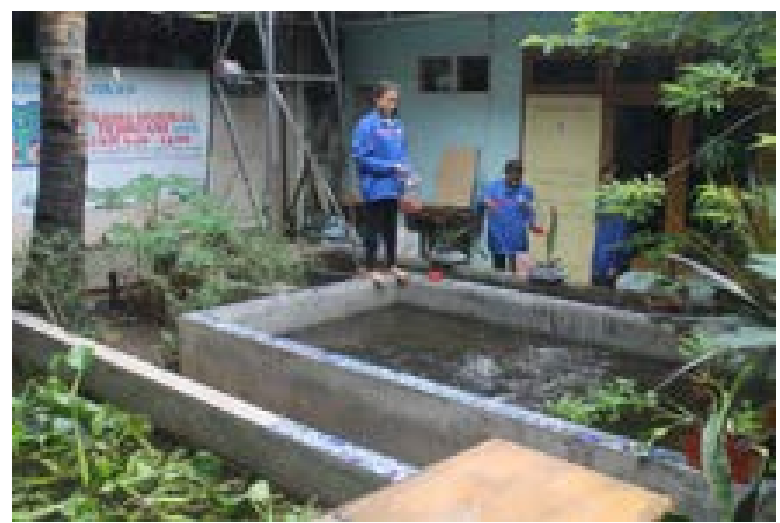

Gambar 6. Budidaya lele

Rencana pengembangan unit-unit usaha baru seperti Pertanian Organik berlokasi di Cidahu, Sukabumi; dalam kemitraan dengan Batu Tapak Camping Ground.

Berdasarkan uraian diatas, maka masalah yang dihadapi oleh mitra adalah masih terbatasnya fasilitas pendukung, seperti ruangan-ruangan, sarana IT dan sarana pelatihan. Masalah lainnya adalah kurangnya tenaga professional untuk bidang pengembangan dan pendampingan kewirausahaan. Kebutuhan riil YPU adalah perlu adanya kemitraan dalam sarana IT dan laboratorium pengembangan diri. Selain itu perlu adanya guru atau dosen pengajar atau tutor.

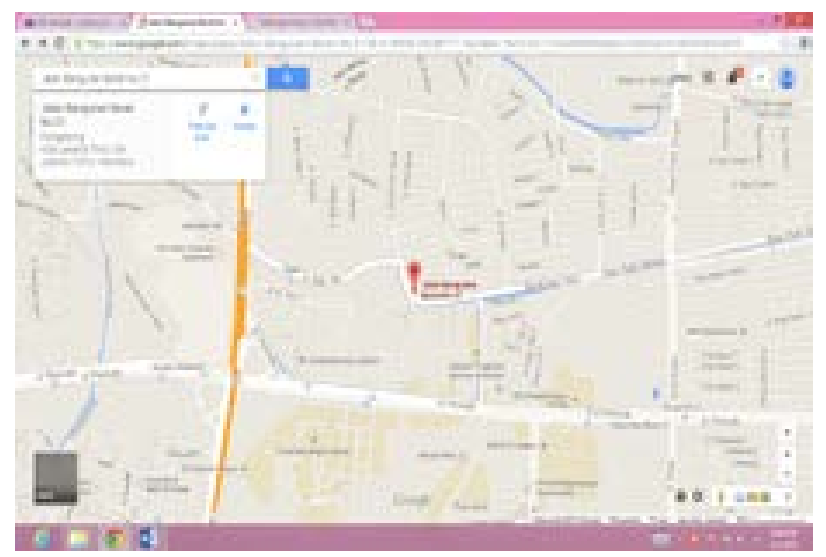

Gambar 7. Lokasi Mitra

\section{METODE PELAKSANAAN}

\section{A. Topik Kegiatan}

Sebagai program studi yang terkait dengan bidang teknologi dan bisnis maka Prodi Sistem Informasi Kalbis Institute sangat antusias untuk ikut berpartisipasi dalam kegiatan PKM gabungan antara Kalbis dengan Yayasan Prima Unggul.

Berdasarkan visi dari mitra sendiri yang ingin melahirkan 10000 entrepreneur dari anak-anak panti maka Prodi Sistem Informasi mengusulkan beberapa konsep pelatihan terkait dengan teknologi. Selain itu pelatihan ini nantinya sangat mendukung 
dalam mencetak entrepreneur ke depannya melalui penciptaan dan pengembangan sebuah unit usaha bisnis. Dari beberapa pertimbangan yang ada maka Prodi Sistem Informasi mengusulkan untuk memberikan pelatihan desain grafis menggunakan perangkat adobe photoshop untuk melakukan manipulasi foto bagi tim teknologi informasi YPU.

\section{B. Tujuan Kegiatan}

Tujuan Kegiatan secara khusus adalah diharapkan anak-anak dari Yayasan Prima Unggul punya keahlian secara praktikal untuk membuat desain logo, kop surat, undangan, sablon, spanduk, brosur, poster, edit foto dan lain-lain. Secara Umum adalah Dari keahlian itu maka nantinya Yayasan Prima Unggul (YPU) dapat mulai merintis untuk memiliki unit usaha baru yaitu bidang desain grafis. Diharapkan unit usaha ini nantinya dapat berperan sebagai salah satu sumber pendanaan/operasional di YPU.

\section{Manfaat Kegiatan}

Manfaat kegiatan bagi Program Studi Sistem Informasi adalah pemenuhan kewajiban Pengabdian Pada Masyarakat bagi Dosen Prodi, meningkatkan keahlian dosen melalui proses sharing keahlian bagi anak-anak di YPU, memperbanyak relasi dengan mitra untuk berbagai fungsi-fungsi positif, memberikan pengalaman baru bagi dosen - dosen Prodi. Mengenai pemamfaatan Teknologi bagi penciptaan entrepreneur-enterpreneur baru.

Manfaat kegiatan bagi YPU adalah meningkatkan keahlian secara praktikal mengenai desain grafis, memberikan pengenalan mengenai konsep dan perangkat pendukung desain grafis, memberikan peluang bagi YPU untuk merintis unit usaha baru bidang desain grafis, memberikan pemahaman-pemahaman baru mengenai dunia kampus Kalbis Institute.

\section{Metode Pendekatan}

Sesuai dengan permasalahan diatas, maka Dosen Program Studi Sistem Informasi Fakultas Ilmu Komputer dan Ilmu Komunikasi Institut Teknologi dan Bisnis Kalbe (Institut Teknologi dan Bisnis Kalbe) akan mengadakan pelatihan dengan tema "pelatihan desain grafis menggunakan perangkat adobe photoshop untuk melakukan manipulasi foto bagi tim teknologi informasi YPU - Jakarta Timur" pada tanggal 13 Maret 2014 yang bertempat di Laboratorium Komputer Kalbis Institute di Jalan Pulomas Selatan Kav.22 Jakarta Timur.
Tema pelatihan yang ditawarkan adalah: Tools pada Photoshop; Area kerja Photoshop; Toolbox pada Photoshop; Palet yang ada pada Photoshop; Mengganti warna cahaya; Mengisolasi warna; Mural; Melukis Pantai; Membuat Foto Sephia; dan Membuat Foto Perangko

\section{E. Tinjauan Pustaka}

\section{Adobe Photoshop}

Adobe Photoshop, atau biasa disebut Photoshop, adalah perangkat lunak editor citra buatan Adobe Systems yang dikhususkan untuk pengeditan foto/ gambar dan pembuatan efek. Perangkat lunak ini banyak digunakan oleh fotografer digital dan perusahaan iklan sehingga dianggap sebagai pemimpin pasar (market leader) untuk perangkat lunak pengolah gambar/foto, dan, bersama Adobe Acrobat, dianggap sebagai produk terbaik yang pernah diproduksi oleh Adobe Systems. Versi kedelapan aplikasi ini disebut dengan nama Photoshop CS (Creative Suite), versi sembilan disebut Adobe Photoshop CS2, versi sepuluh disebut Adobe Photoshop CS3, versi kesebelas adalah Adobe Photoshop CS4, versi keduabelas adalah Adobe Photoshop CS5, versi ketigabelas adalah CS6, dan versi terbaru adalah Adobe Photoshop CC.

Photoshop tersedia untuk Microsoft Windows, Mac OS X, dan Mac OS; versi 9 ke atas juga dapat digunakan oleh sistem operasi lain seperti Linux dengan bantuan perangkat lunak tertentu seperti CrossOver.

\section{Pengembangan}

Pada tahun 1987, Thomas Knoll, mahasiswa $\mathrm{PhD}$ di Universitas Michigan, mulai menulis sebuah program pada Macintosh Plus-nya untuk menampilkan gambar grayscale pada layar monokrom. Program ini, yang disebut Display, menarik perhatian saudaranya John Knoll, seorang karyawan di Industrial Light \& Magic, yang merekomendasikan Thomas agar mengubah programnya menjadi program penyunting gambar penuh. Thomas mengambil enam bulan istirahat dari studi pada tahun 1988 untuk berkolaborasi dengan saudaranya pada program itu, yang telah diubah namanya menjadi ImagePro. Setelah tahun itu, Thomas mengubah nama programnya menjadi Photoshop dan bekerja dalam jangka pendek dengan produsen scanner Barneyscan untuk mendistribusikan salinan dari program tersebut dengan slide scanner; "total sekitar 200 salinan Photoshop telah dikirimkan" dengan cara ini. (Schewe, 2000). Selama waktu itu, John bepergian ke Silicon Valley di California dan memberikan demonstrasi 
program itu kepada insinyur di Apple Computer Inc. dan Russell Brown, direktur seni di Adobe. Kedua demonstrasi itu berhasil, dan Adobe memutuskan untuk membeli lisensi untuk mendistribusikan pada bulan September 1988. Sementara John bekerja pada plug-in di California, Thomas tetap di Ann Arbor untuk menulis kode program. Photoshop 1.0 dirilis pada 1990 khusus untuk Macintosh. (Hormby, 2007).

\section{Fitur}

Meskipun pada awalnya Photoshop dirancang untuk menyunting gambar untuk cetakan berbasiskertas, Photoshop yang ada saat ini juga dapat digunakan untuk memproduksi gambar untuk World Wide Web. Beberapa versi terakhir juga menyertakan aplikasi tambahan, Adobe ImageReady, untuk keperluan tersebut.

Photoshop juga memiliki hubungan erat dengan beberapa perangkat lunak penyunting media, animasi, dan authoring buatan-Adobe lainnya. File format asli Photoshop, .PSD, dapat diekspor ke dan dari Adobe ImageReady. Adobe Illustrator, Adobe Premiere Pro, After Effects dan Adobe Encore DVD untuk membuat DVD profesional, menyediakan penyuntingan gambar non-linear dan layanan special effect seperti background, tekstur, dan lain-lain untuk keperluan televisi, film, dan situs web. Sebagai contoh, Photoshop CS dapat digunakan untuk membuat menu dan tombol (button) DVD. Photoshop dapat menerima penggunaan beberapa model warna: RGB color model; Lab color model; CMYK color model; Grayscale; Bitmap; Duotone

Versi yang dirilis pada tahun 2005, adalah versi 9. Program ini dipasarkan dengan nama "Photoshop CS2." "CS" merefleksikan integrasi produk Photoshop dengan aplikasi "Creative Suite buatan Adobe dan disebut " 2 " karena program ini adalah versi rilis ke-2 sejak Adobe mengintegrasikan kedua produknya. Ada beberapa pada tambahan pada Photoshop CS2 seperti multiple layer selecting dan "warp," versi kurva dari transform tool dan color replacement tool, yang sebelumnya hadir sebagai plug-in 8BF.

Untuk para penggemar fotografi, Adobe menyediakan filter "reduce grain" (mengurangi grain) yang dapat membantu mengoptimalkan foto yang diambil pada kondisi kekurangan cahaya. Untuk "memperjelas" perbedaan produk CS dengan produk Photoshop sebelumnya, Adobe menghilangkan lambang mata Photshop, yang dipresentasikan dalam bentuk yang berbeda-beda sejak versi 3 sampai versi 7. Photoshop CS dan CS2 kini menggunakan bulu sebagai ikon dan bentuk identifikasinya.

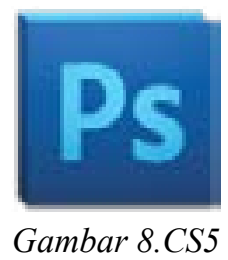

Versi beta Photoshop CS3 telah dirilis untuk pengguna CS2 pada tanggal 15 Desember 2006. Berbeda dengan Photoshop CS dan CS2 yang menggunakan bulu sebagai logonya, Logo untuk edisi ketiga ini berbentuk tipografi, dengan huruf 'Ps' berwarna putih dan berlatar belakang biru-gradien.

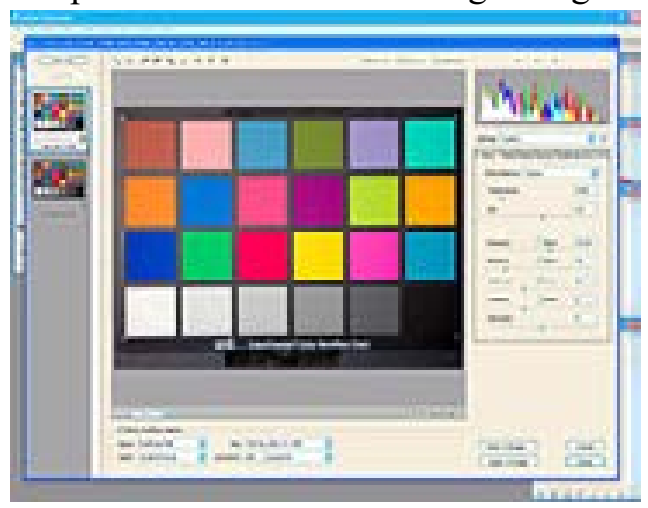

Gambar 9. Camera RAW 3.x

Versi terakhirnya dilengkapi dengan Adobe Camera $R A W$, sebuah plugin yang dikembangkan oleh Thomas Knoll yang dapat membaca beberapa format file RAW dari kamera digital dan mengimpornya langsung ke Photoshop. Versi awal RAW plugin ini juga tersedia untuk Photoshop 7.0.1 dengan tambahan biaya \$99 USD.

Secara Photoshop adalah sebuah program penyunting gambar standar industri yang ditujukan untuk para profsional raster grafik, harga yang ditawarkan pun cukup tinggi; kira-kira US\$600. Keadaan ini memancing beberapa programer untuk merancang peralatan grafik (graphics tools) dengan harga yang lebih terjangkau. Untuk menghadapi persaingan ini, dan untuk menghadapi pembajakan produknya, Adobe memperkenalkan Photoshop Elements, sebuah versi lain dari Photoshop yang lebih minimalis, dengan harga terjangkau; di bawah US\$100. Produk ini ditujukan untuk pengguna rumahan dan menghilangkan beberapa fitur profesional.

\section{Format File}

Photoshop memiliki kemampuan untuk membaca dan menulis gambar berformat raster seperti .png, .gif, .jpeg, dan lain-lain. Photoshop juga memiliki beberapa format file khas: .PSD (Photoshop Document) format yang menyimpan gambar dalam bentuk layer, termasuk teks, mask, opacity, blend 
mode, channel warna, channel alpha, clipping paths, dan setting duotone. Kepopuleran photoshop membuat format file ini digunakan secara luas, sehingga memaksa programer program penyunting gambar lainnya menambahkan kemampuan untuk membaca format PSD dalam perangkat lunak mereka; .PSB' adalah versi terbaru dari PSD yang didesain untuk file yang berukuran lebih dari $2 \mathrm{~GB}$; dan .PDD adalah versi lain dari PSD yang hanya dapat mendukung fitur perangkat lunak PhotoshopDeluxe. (Al-Amin, 2004).

\section{Tool}

Tool dalam Adobe Photoshop adalah alat yang dapat membantu pengguna dalam mengedit. Adobe Photoshop CS3 memilikit 59 tool yang dapat dipakai oleh pengguna. Tool-tool tersebut terdiri dari berbagai macam tool dengan kegunaan yang spesifik. Beberapa tool-tool yang ada di Photoshop antara lain: Move Tool; History Brush Tool; Eraser Tool; Path Selection Tool; Direct Selection tool; Pen Tool; Shape Tool; Brush Tool; Audio Annotation Tool; Eyedropper Tool; Measure Tool; Text Tool; Hand Tool; 3D Object Rotate Tool; dan 3D Rotate Camera Tool

\section{Dampak Terhadap Industri}

Pengembangan manipulasi gambar digital banyak memengaruhi industri fotografi. Pengembangan tersebut menciptakan seni pengolah gambar (photo retouching) dan mengubah cara kerja: produk yang biasanya hanya dapat diciptakan oleh fotografer profesional selama berjam-jam atau bahkan berhari-hari, kini dapat diproduksi oleh seniman amatir sekalipun. Manipulasi gambar digital telah menyumbang begitu banyak hal kepada dunia fotografi dengan memungkinkan manipulasi yang awalnya sulit atau bahkan tak mungkin. Photoshop berperan besar dalam perkembangan dunia digital saat ini.

Pada masa revolusi fotografi digital pada tahun 90-an, Photoshop menjadi standar di dunia industri. Banyak fotografer yang menggunakan program ini untuk mengoptimalkan hasil akhir foto yang mereka ciptakan. Dengan kehadiran tablet grafik, terutama dari Wacom, program seperti Adobe Photoshop dan Corel Painter semakin dibutuhkan untuk menciptakan gambar orisinal. Dengan menggunakan pressure sensitive tablet dapat meningkatkan efek paint brush, eraser, atau tool lainnya. Tablet digunakan secara global oleh para ilustrator komik profesional, arsitek, seniman studio, dan lainnya. Bahkan ILM, perusahaan spesial efek yang berperan dalam produksi film Star Wars, menggunakan tablet yang dikombinasikan dengan Photoshop untuk mengoptimalkan hasil-produksinya.

Sebenarnya fungsi utama dari Adobe Photoshop hanyalah untuk aplikasi pengedit foto ataupun gambar dengan tipe raster atau bitmap. Namun sebagai aplikasi pengedit gambar, fungsi Photoshop dapat dijabarkan lebih khusus lagi, yaitu untuk mempercantik gambar, merekayasa gambar, dan membuat desain gambar. (Al-Amin, 2004)

\section{Fungsi Photoshop}

Fungsi Photoshop untuk mempercantik gambar yaitu dengan cara menghaluskan atau objek, dimana hal ini dilakukan agar gambar tersebut terlihat lebih menarik dan indah. Fungsi Photoshop juga untuk merekayasa gambar yaitu dengan cara merubah tampilan ataupun menggabungkan gambar-gambar yang berbeda agar gambar tersebut terlihat seperti gambar asli dan seringkali dapat menipu mata yang melihatnya. Dan fungsi Photoshop untuk membuat desain gambar yaitu dengan cara menciptakan objek baru seperti logo, brosur, spanduk, dan poster.

Adapun fungsi adobe photoshop secara teknik: Mengkombinasi 2 gambar atau lebih menjadi satu gambar baru; Menghilangkan atau menghapus objek pada suatu gambar; Memberi atau merubah warna; Merubah ukuran gambar menjadi lebih kecil ataupun menjadi lebih besar; Mempertajam warna dan kualitas gambar; Membersihkan atau memperindah gambar; Mengaburkan gambar agar terlihat samar-samar; Meningkatkan intensitas cahaya gambar agar terlihat lebih terang; dan Memotong gambar

Pada aplikasi Photoshop terdapat beberapa bagian penting lain yang juga memiliki fungsi-fungsi tersendiri. Bagian-bagian tersebut seperti tool,menu, toolbox,layer, dan lainnya. Berikut adalah beberapa bagian penting Photoshop beserta fungsinya: a)Layer : sebagai kanvas tempat mendesain gambar. Di dalam Photoshop kita dapat menggunakan lebih dari satu layer. Kelebihan dalam pemakaian banyak layer adalah setiap desain pada satu layer tidak akan mengganggu suatu desain pada layer lain. Dan semua desain yang ada pada layer-layer bisa dikombinasikan menjadi satu gambar; b) Tool : alat-alat yang digunakan untuk mendesain atau menyunting gambar; c) Menu : tempat utama dimana semua tool Photoshop berada. Menu inti yang ada di Photoshop : File, Layer,Edit, Image, Window, Select, 3D,Filter, Analysis, View, dan Help; d) Toolbox : tempat khusus yang menyediakan tooltool penting agar lebih mudah dilihat dan dipakai. 


\section{Kelebihan Adobe Photoshop:}

Adapun kelebihan dari Photoshop: Gambar yang dihasilkan lebih memuaskan; Mudah di operasikan; Banyak fitur - fitur yang unggul; Bisa di gunakan untuk membuat tulisan dengan efek yang di inginkan. Buat anda yang ingin membuat tulisan tampil beda dan menakjubkan Photoshop adalah jawabannya; Bisa di gunakan untuk mendesain maupun untuk editing gambar; Bisa membuat beragam material; Bisa juga di gunakan untuk mengolah beberapa materi web. Buat anda yang mempunyai web dan akan mengupload foto tetapi ukuran foto terlalu besar, Anda tidak perlu khawatir karena photoshop dapat di andalkan untuk hal ini; Familyar dalam kalangan kita; Fasilitas untuk editing lebih lengkap di banding lainnya; Bisa untuk rekayasa foto. Di dalam Photoshop anda dapat bebas berekspresi foto asli yang anda punya dapat di ubah menjadi lebih keren dan menarik; Bisa menambah efek lagi meski sudah terlalu banya efek; Penyimpanan dapat menggunakan berbagai format. Format penyimpanan pada photoshop tidak sekedar PSD, namun JPEG, PNG dan yang lainnya; dan Photoshop lebih cepat kerjanya.

\section{Kekurangan Adobe Photoshop :}

Adapun kekurangan Photoshop adalah: Banyaknya layer yang di gunakan membuat orang bingung ketika menggunakan photoshop; Photoshop kurang baik saat digunakan untuk pembuatan majalah dan brosur karena tidak bisa sempurna saat pembuatan paragraf; Ukuran yang di butuhkan terlalu besar. Nah jika kita terlalu banyak menggunakan layer maka ukuran di Photoshop akan besar; dan Saat akan mencetak hasil Photoshop kertas yang digunakan relatif sulit.

\section{HASIL DAN PEMBAHASAN}

Deskripsi kegiatan pengabdian kepada masyarakat yaitu "Pelatihan Desain Grafis Menggunakan Perangkat Adobe Photoshop untuk Melakukan Manipulasi Foto bagi Tim Tenologi Informasi Yayasan Prima Unggul - Jakarta Timur" tanggal 13 Maret 2014 adalah sebagai berikut:

\section{A. Perencanaan Kegiatan PKM}

Rencana ini didiskusikan dalam rapat Tim Dosen Program Studi Sistem Informasi Fakultas Ilmu Komputer dan Ilmu Komunikasi Institut Teknologi dan Bisnis Kalbe (Kalbis Institute) yang tergabung kedalam Tim Pengabdian Kepada Masyarakat (PKM) pada 15 Januari 2014 jam 08.00
- 12.00 di ruang dosen Lantai 2 Kampus Institut Teknologi dan Bisnis Kalbe (Kalbis Institute) Jalan Pulomas Selatan Kav.22 Jakarta Timur. Diskusi ini untuk membicarakan PKM yang merupakan salah satu wujud Tri Dharma Perguruan Tinggi. Hasilnya adalah kesepakatan untuk melakukan PKM dengan mitra Yayasan Prima Unggul - Jakarta Timur. Alasan utama untuk melakukan PKM di dengan mitra YPU adalah karena lokasinya yang tidak terlalu jauh dari kampus Institut Teknologi dan Bisnis Kalbe (Kalbis Institute), yaitu berjarak sekitar 1,2 km.

\section{B. Observasi awal tim PKM ke Yayasan Prima Unggul}

Kegiatan ini dilakukan pada tanggal 23 Januari 2014 jam 08.00 - 17.00, bertempat di Yayasan Prima Unggul, Jl. Bangunan Timur No.31, Kelurahan Kayu Putih, Jakarta Timur tanggal 23 Januari 2014 jam 08.00 - 17.00 untuk hal: Perkenalan kegiatan PKM Prodi Sistem Informasi oleh tim PKM kepada Yayasan Prima Unggul; Pengenalan profil Yayasan Prima Unggul; dan Pemberian saran-saran dari para pendidik Yayasan Prima Unggul agar kegiatan pengabdian masyarakat tepat sasaran dan bermanfaat bagi para guru dan peserta didik YPU.

\section{Penentuan program dan tema PKM}

Dalam rapat Tim PKM pada 30 Januari 2014 jam 08.00 - 12.00 di ruang dosen Lantai 2 Kampus Institut Teknologi dan Bisnis Kalbe (Kalbis Institute) alan Pulomas Selatan Kav.22 Jakarta Timur dibicarakan program dan tema PKM yang diberikan bagi tim teknologi informasi Yayasan Prima Unggul. Hasilnya adalah kesepakatan untuk mengadakan PKM dengan tema "Pelatihan Desain Grafis Menggunakan Perangkat Adobe Photoshop Untuk Melakukan Manipulasi Foto Bagi Tim Teknologi Informasi Yayasan Prima Unggul" pada tanggal 13 Maret 2014 yang bertempat di Laboratorium Komputer Kalbis Institute di Jalan Pulomas Selatan Kav.22 Jakarta Timur.

\section{Observasi Lanjutan Tim Pengabdian Kepada Masyarakat ke Yayasan Prima Unggul}

Kegiatan observasi lanjutan tim Pengabdian Kepada Masyarakat ke Yayasan Prima Unggul, Jl. Bangunan Timur No.31, Kelurahan Kayu Putih, Jakarta Timur tanggal 3 Februari 2014 jam 08.00 17.00. Observasi ini untuk mengetahui: Pengenalan profil guru dan peserta didik Yayasan Prima Unggul; dan Identifikasi permasalahan spesifik yang sedang dihadapi mitra. 
Beberapa foto kegiatan observasi Tim PKM ke YPU dapat dilihat pada gambar 10, gambar 11, dan gambar 12 .

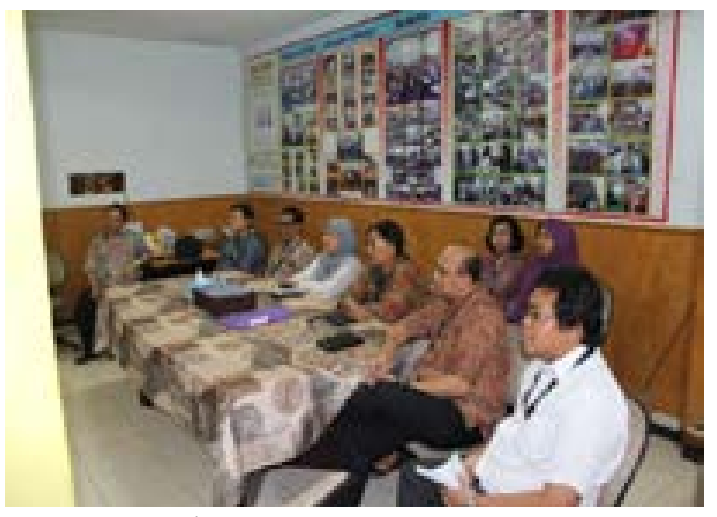

Gambar 10. Ketua YPU Martinus Mesarudi Gea bersama tim PKM Kalbis Institute

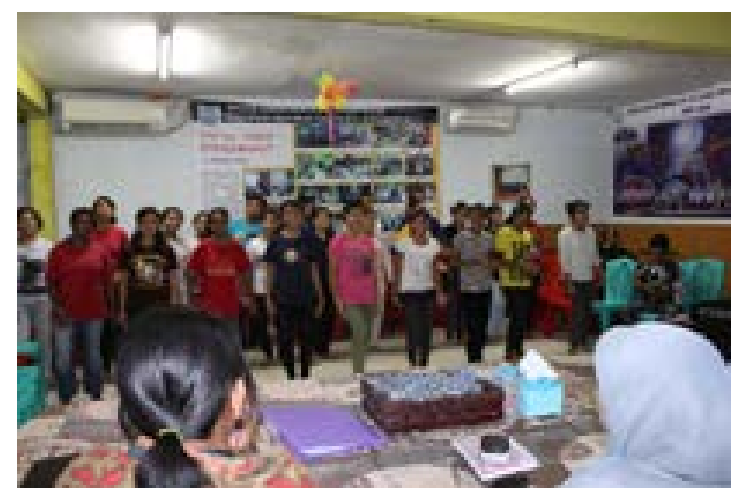

Gambar 11. Siswa YPU menyanyikan lagu menyambut Tim PKM dari Kalbis Institut

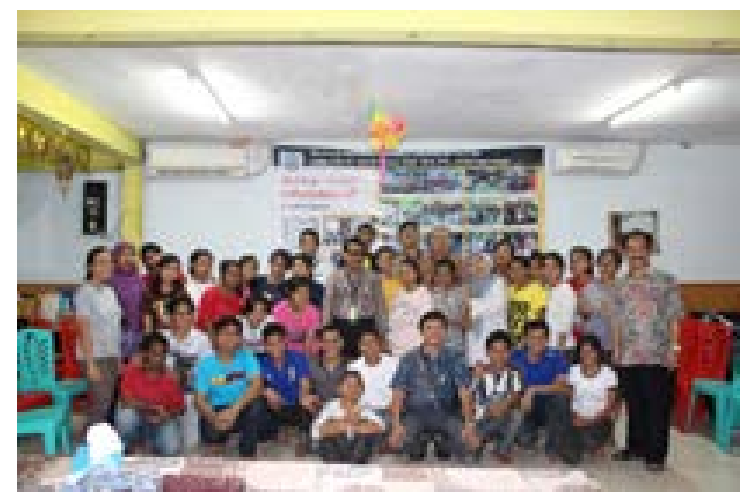

Gambar 12. Kepala Biro P3KM Hadi Sutopo, Ketua YPU Bpk Martinus Mesarudi Gea, tim PKM dan siswa YPU

\section{E. Rapat Koordinasi tim PKM dengan pendiri, romo, dan peserta didik YPU}

Kegiatan ini dilakukan pada tanggal 6 Februari 2014 jam 08.00 - 17.00 di Ruang rapat Yudhistira Lantai 2 Gedung Kalbis Institute Jl. Pulomas Selatan Kav.22 Jakarta Timur. Rapat ini untuk membicarakan: Koordinasi tema pelatihan yang dibutuhkan oleh YPU; Koordinasi waktu dan tempat pelaksanaan kegiatan PKM.
Beberapa foto kegiatan koordinasi tim PKM dan tim YPU dilihat pada gambar 13 dan gambar 14.

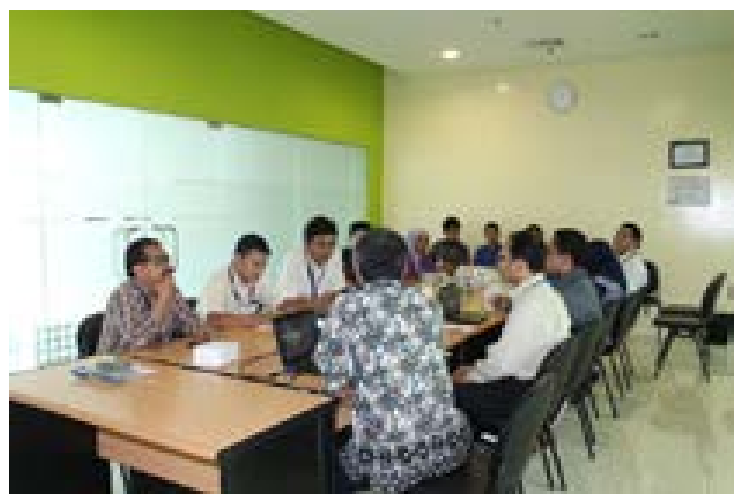

Gambar 13. Rapat koordinasi tim PKM dengan YPU 6 Februari 2014 di Kalbis Institute

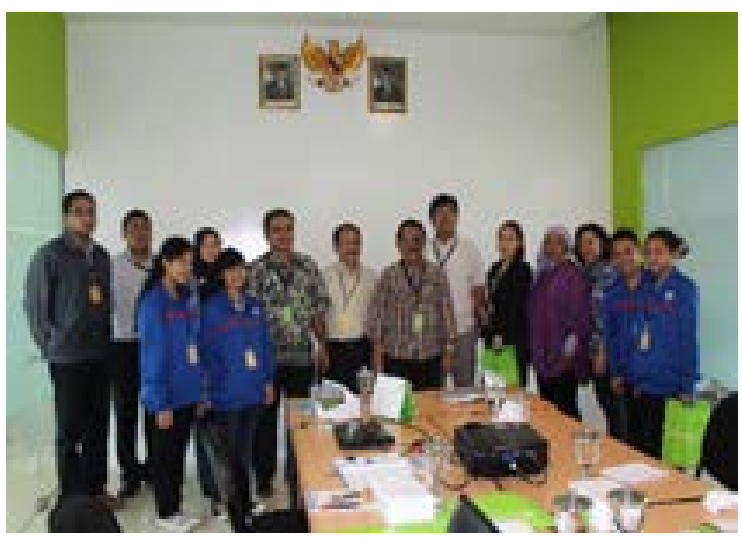

Gambar 14. Tim PKM, ketua dan siswa YPU seusai rapat koordinasi

\section{F. Identifikasi permasalahan spesifik yang sedang dihadapi mitra.}

Persoalan mitra dapat diidentifikasi dengan melakukan observasi lanjutan tim PKM yaitu berdiskusi dengan para guru madrasah tersebut untuk mengetahui profil guru agar materi pelatihan yang akan diberikan sesuai dengan kebutuhan mereka.

\section{G. Pembuatan proposal PKM}

Pembuatan proposal PKM "Pelatihan Desain Grafis Menggunakan Perangkat Adobe Photoshop Untuk Melakukan Manipulasi Foto Bagi Tim Teknologi Informasi Yayasan Prima Unggul" tanggal 13 Februari 2014 jam 08.00 - 12.00 oleh tim PKM.

\section{H. Pembuatan materi pelatihan yang sesuai dengan persoalan mitra}

Dalam rapat Tim PKM pada 21 Februari 2014 di ruang dosen Lantai 2 Kampus Institut Teknologi dan Bisnis Kalbe (Kalbis Institute) Jl. Pulomas Selatan Kav.22 Jakarta Timur dibicarakan materi yang akan diberikan pada acara PKM 13 Maret 2014 dengan tema "Pelatihan Desain Grafis 
Menggunakan Perangkat Adobe Photoshop Untuk Melakukan Manipulasi Foto Bagi Tim Teknologi Informasi Yayasan Prima Unggul". Hasilnya adalah kesepakatan untuk membuat materi pelatihan yang berjudul "Desain Grafis dengan Adobe Photoshop" yang berisi 10 modul.

\section{Penugasan PKM oleh Kepala Biro P3KM ITBK}

Penugasan kegiatan PKM dengan mitra yaitu Yayasan Prima Unggul - Jakarta Timur ditunjukkan dengan adanya Surat Tugas no 030/P3KM-STU/ III/2014 tanggal 12 Maret 2014 yang ditandatangani oleh Kepala Biro P3KM-ITBK Bapak Dr. Hadi Sutopo S.Kom, MMSI.

\section{J. Pelaksanaan Pelatihan}

Kegiatan pelatihan dilaksanakan tanggal 13 Maret 2014 jam 08.00 - 17.00 WIB, bertempat di Laboratorium Komputer Lantai 5 Kampus Kalbis Institute Jalan Pulomas Selatan Kav.22 Jakarta Timur. Pelatihan diberikan oleh Tim PKM dari Prodi Sistem Informasi yang berjumlah sebanyak 7 (tujuh) orang dosen dan 3 (tiga) orang mahasiswa. Peserta pelatihan adalah tim teknologi informasi Yayasan Prima Unggul yang berjumlah 17 orang.

Acara dimulai dengan meregistrasi peserta jam 08.00 - 09.00 WIB, dilanjutkan pembukaan oleh Kepala Biro P3KM-ITBK Bpk Dr. Hadi Sutopo, S.Kom, MMSI. Beliau menyampaikan bahwa kegiatan pengabdian kepada masyarakat merupakan salah satu wujud Tri Dharma Perguruan Tinggi. Beliau juga mengucapkan terima kasih atas kehadiran dan partisipasi ketua, guru, dan siswa Yayasan Prima Unggul. Beliau juga berharap semoga kegiatan pengabdian kepada masyarakat ini memberikan manfaat bagi para guru dan siswa YPU dalam meningkatkan pengetahuan dan mendukung unit usaha yang ada di YPU. Dilanjutkan dengan sambutan dari Ketua Yayasan Prima Unggul oleh Martinus Mesarudi Gea. Dalam sambutannya beliau mengucapkan terima kasih atas dilibatkannya YPU sebagai mitra PKM prodi Sistem Informasi. Beliau juga berharap semoga pelatihan ini tidak hanya sekali saja dan bisa berkesinambungan karena materi pelatihan yang diberikan sangat dibutuhkan oleh siswa maupun guru-guru YPU dalam meningkatkan pengetahuan untuk bisa mendukung unit usaha dalam mewujudkan visi melahirkan enterpreneur dari anakanak panti Yayasan Prima Unggul.

Jam 9.30 - 10.45 WIB acara dilanjutkan dengan pelatihan Modul 1 yaitu: Tools pada Photoshop, Area kerja Photoshop dan Toolbox pada Photoshop dengan instruktur Ibu Ridha Sefina Samosir, S.Si, M.Kom dan Bapak Bruce Hanadi, ST, M.Sc.Is. Jam 10.45 - 12.00 WIB dilanjutkan dengan pelatihan Modul 2 yaitu: Palet yang ada pada Photoshop, Mengganti warna cahaya dan Mengisolasi warna dengan instruktur Varian Adriel Zakharp Noor dan Ibu Mira Ziveria, S.Si, MT.

Setelah istirahat untuk makan siang jam 13.00 - 14.15 WIB acara kembali dilanjutkan dengan pelatihan Modul 3 yaitu: Mural dan Melukis Pantai dengan instruktur Bapak R. Wisnu Pamungkas, S.Kom, M.Kom dan Bapak Erwin Syah Rani, S.Kom, M.MSI. Jam 14.15 - 15.30 WIB acara dilanjutkan dengan pelatihan Modul 4 yaitu: Membuat Foto Sephia dan Membuat Foto Perangko dengan instruktur Bapak Drs. Muhammad Rusli, MM dan Bapak Edy Winarso, S.Kom, MM.

Jam 15.30 - 16.30 WIB acara dilanjutkan dengan "Latihan Manipulasi Foto". Pada sesi latihan ini peserta diberikan sebuah foto, lalu peserta diminta untuk memanipulasi foto tersebut sesuai dengan kreatifitas mereka dengan menggunakan tools adobe photoshop yang sudah diberikan sebelumnya.

Jam 16.30 - 17.00 WIB, dilanjutkan dengan pemberian sertifikat kepada semua peserta pelatihan. Pada akhirnya acara ditutup oleh Ibu Mira Ziveria, S.Si, MT, selaku ketua pelaksana PKM.

Pelaksanaan kegiatan pelatihan yang dilaksanakan tgl 13 Maret 2014 jam 08.00 - 17.00 WIB di Lab Komputer Kalbis Institute ini ditunjukkan dengan Surat Keterangan No. No.21/YPU/III/2014 yang ditandatangani oleh Ketua Yayasan Prima Unggul Bpk Martinus Mesarudi Gea.

Beberapa foto kegiatan pelaksanaan pelatihan oleh tim PKM untuk siswa YPU dilihat pada gambar 15, gambar 16, dan gambar 17.

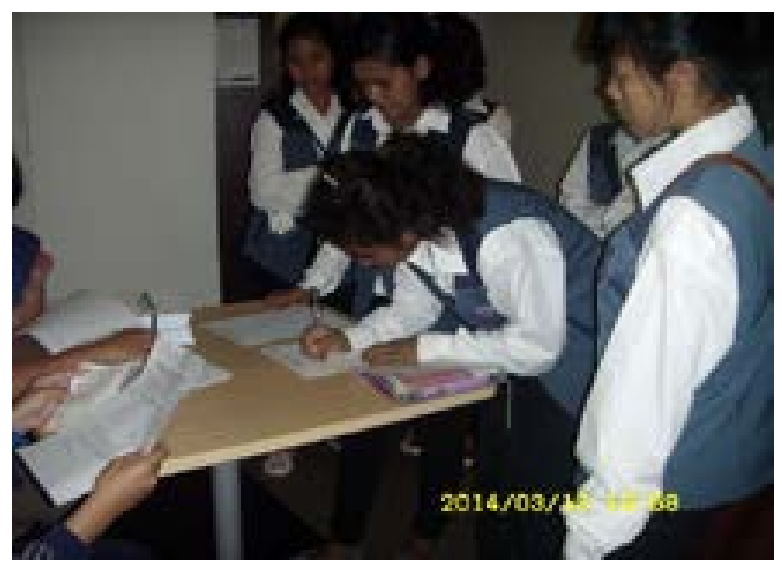

Gambar 15. Registrasi peserta pelatihan jam $08.00-09.00$ WIB di Lantai 5 gedung Kalbis Institute 


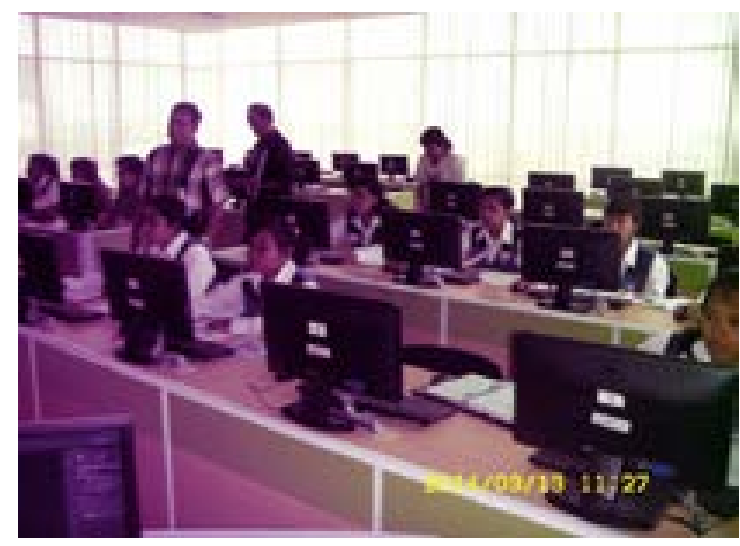

Gambar 16. Suasana saat pelatihan

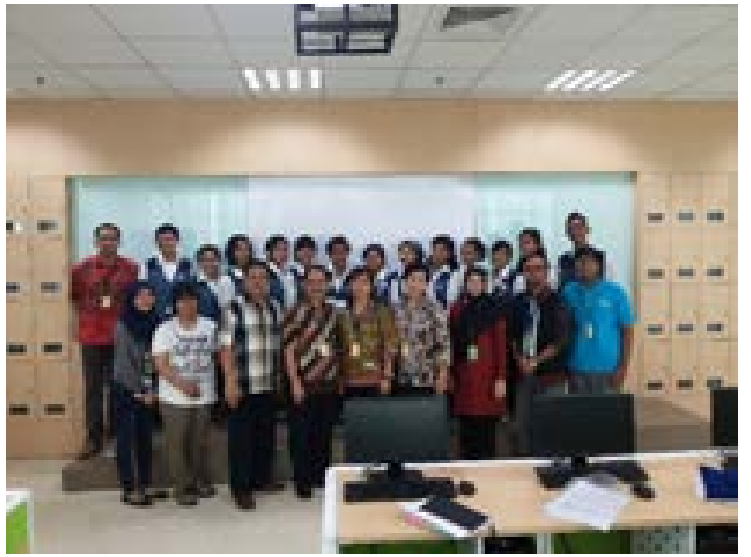

Gambar 17. Tim PKM, ketua, guru, dan siswa-siswi YPU yang menjadi peserta pelatihan

Tabel 1 Jadwal pelatihan dan metode pendekatan

\begin{tabular}{|c|c|c|}
\hline \multicolumn{3}{|c|}{ I3 Maret 2014} \\
\hline Waktu & Kegiatan & Pelaksana \\
\hline $05.00-09.00$ & Registrasi Peserta & TI PKCW \\
\hline $09.00-09.15$ & $\begin{array}{l}\text { Pembucam oleh } \\
\text { Kerala Buro P3KM }\end{array}$ & $\begin{array}{l}\text { Dr. Hadi Sutopo, S.Kom, } \\
\text { MOMSI }\end{array}$ \\
\hline $09.15-09.30$ & $\begin{array}{l}\text { Sambutas Ketua } \\
\text { Yayasan Prima } \\
\text { Unggul }\end{array}$ & Martinas Merarodi Cea \\
\hline $09.30-10.45$ & $\begin{array}{l}\text { Modial 1, 2, } 3 \text { yzitu } \\
\text { Tools pada } \\
\text { Photoshop, Area } \\
\text { kejia Photoshop. } \\
\text { Toolbox pads } \\
\text { Photoshop }\end{array}$ & $\begin{array}{l}\text { Ridha Sefina Samosir, } \\
\text { S.Si, MKom dan Broce } \\
\text { Hanadi, ST, MLSc Is }\end{array}$ \\
\hline $10.45-12.00$ & 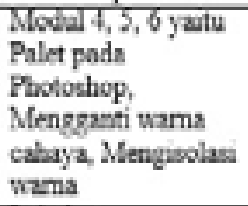 & $\begin{array}{l}\text { Varan Adne Zakhap } \\
\text { Noor } \\
\text { Mua Zivena, S.Si, MT }\end{array}$ \\
\hline $1200-1300$ & Estinzast & \\
\hline $13.00-14.15$ & $\begin{array}{l}\text { Modal } 7,8 \text { yzitu } \\
\text { Moral, Melubis } \\
\text { Pantas }\end{array}$ & $\begin{array}{l}\text { R. Wismu Pamungkas, } \\
\text { S.Kom, M.Koen dan } \\
\text { Erwin Syah Rani. S.Kom, } \\
\text { MMSI }\end{array}$ \\
\hline $14.15-1530$ & $\begin{array}{l}\text { Modu9, } 10 \text { yzitu } \\
\text { Membuat Foto } \\
\text { Sephis, Membuat } \\
\text { Fowo Perangko }\end{array}$ & $\begin{array}{l}\text { Drs, Muhammad Rusti, } \\
\text { MQM dan Edy Winareo, } \\
\text { S.Koen, MDM }\end{array}$ \\
\hline $15.30-16.30$ & $\begin{array}{l}\text { Latihan Manipulasi } \\
\text { Feeo }\end{array}$ & InMTKM \\
\hline $16.30-16.35$ & $\begin{array}{l}\text { Penyerahan } \\
\text { Sertifikat }\end{array}$ & Tim PKM \\
\hline $16.45-17,00$ & Penutup & $\begin{array}{l}\text { Ridha Sefina Samodir, } \\
\text { S.St, M.Kom }\end{array}$ \\
\hline
\end{tabular}

\section{K. Evaluasi dan pembuatan laporan akhir}

Evaluasi dan pembuatan laporan akhir atas pelatihan yang telah diberikan 28 Maret 2014 jam 08.00 - 12.00 di ruang dosen Lantai 2 Kampus Institut Teknologi dan Bisnis Kalbe (Kalbis Institute) Jl. Pulomas Selatan Kav.22 Jakarta Timur.

\section{Jadwal Pelatihan dan Metode Pendekatan}

Jadwal pelatihan dan metode pendekatan seperti pada Tabel 1

\section{SIMPULAN}

Hasil yang diperoleh dari kegiatan pengabdian kepada masyarakat ini adalah peserta pelatihan mengenal desain grafis dan dapat menggunakan perangkat adobe photoshop untuk melakukan manipulasi foto.

\section{DAFTAR RUJUKAN}

Al-Amin, M. (2004). Disain Grafis dengan Adobe PhotoShop. STMIK Laksi.

Hormby (2007. How Adobe's Photoshop Was Born. Sory Photography. Diakses tanggal 21 Februari 2014 dari https://id.wikipedia.org/wiki//Adobe_Photoshop

Schewe, Jeff (2000). PhotoshopNews. Diakses tanggal 21 Februari 2014 dari https://id.wikipedia.org/wiki/ Adobe_Photoshop 